This is the peer reviewed version of the following article:

Piombino, P.; Pittari, E.; Gambuti, A.; Curioni, A.; Giacosa, S.; Mattivi, F.; Parpinello, GP G. P.; Rolle, L.; Ugliano, M.; Moio, L., Preliminary sensory characterisation of the diverse astringency of single cultivar Italian red wines and correlation of sub-qualities with chemical composition.

AUSTRALIAN JOURNAL OF GRAPE AND WINE RESEARCH Vol 26 issue 3 pp. 233-246

which has been published in final form at DOI: 10.1111/ajgw.12431

This article may be used for non-commercial purposes in accordance with Wiley Terms and Conditions for Use of Self-Archived Versions. 


\title{
Preliminary sensory characterisation of the diverse astringency of single cultivar Italian red wines and correlation of sub-qualities with chemical composition
}

\author{
E. PITTARI', A. GAMBUTI', A. CURIONI ${ }^{2}$, S. GIACOSA ${ }^{3}$, F. MATTIVI ${ }^{4,5}$, \\ G.P. PARPINELLO 6 , L. ROLLE ${ }^{3}$, M. UGLIANO ${ }^{7}$ and L. MOIO' \\ ' Department of Agricultural Sciences, Division of Vine and Wine Sciences, University of Naples Federico II, Avellino \\ 83100, Italy; ${ }^{2}$ Department of Agronomy, Food, Natural Resources, Animals and Environment, University of Padova, \\ Padova 35020, Italy; ${ }^{3}$ Department of Agricultural, Forestry and Food Sciences, University of Torino, Torino 10095, Italy \\ ${ }^{4}$ Center Agriculture Food Environment, University of Trento, Trento 38123 , Italy; ${ }^{5}$ Department of Food Quality and \\ Nutrition, Fondazione Edmund Mach, Research and Innovation Centre, San Michelle All'Adige 380 I0, Italy; ${ }^{6}$ Department \\ of Agricultural and Food Sciences, University of Bologna, Bologna 40126, Italy; ${ }^{7}$ Department of Biotechnology, University \\ of Verona, Verona 37129, Italy \\ Corresponding author: Professor Paola Piombino, email paola.piombino@unina.it
}

\begin{abstract}
Background and Aims: Italy is the richest grape-producing country in terms of cultivars. Our aims were to describe the diversity of astringency of Italian red wines from 11 cultivars, Teroldego, Corvina, Raboso, Nebbiolo, Sangiovese, Sagrantino, Montepulciano, Cannonau, Aglianico, Primitivo and Nerello, and to test correlations between in-mouth sensory variables and chemical composition.

Methods and Results: A sample sub-set was selected by sorting and then assessed on astringency sub-qualities (drying, harsh, unripe, dynamic, complex, surface smoothness, particulate) and tastes (sweet, acid, bitter). Inter-cultivar differences were detected for six of the seven sub-qualities: three diverse intensities for drying, two for harsh, unripe, dynamic, complex and velvet and none for particulate. Discriminant analysis showed that these sub-qualities allowed a good discrimination of the wines according to the cultivar. Well reclassified samples $(88 \%)$ were considered to develop a single-cultivar 'astringency spectra', profiles describing the balance among sub-qualities. Correlations highlighted that neither total phenols nor proanthocyanidins can predict the perception of all astringency nuances.

Conclusions: For some single cultivar wines, it was possible to identify a pattern of astringency features likely to be linked to the cultivar.

Significance of the Study: This work adds insights to the understanding of astringency sub-qualities while enhancing the knowledge of Italian wines. Results may support the awareness of winemakers of wines from native cultivars, and assist in building models of astringency.
\end{abstract}

Keywords: astringency spectra, astringency sub-quality, diversity, sensory characterisation, single cultivar Italian red wine

\section{Introduction}

According to the Organisation Internationale de la Vigne et du Vin (OIV) (2017), Italy is the grape-producing country with the greatest number of cultivars. This results from centuries of human selection, which has led to a tight cultivarenvironment relationship. This rich ampelographic heritage, composed nowadays of around 500 cultivars-considering those listed in the Italian National Catalogue of Grapevine Varieties (Lacombe et al. 2011)_includes red grapes with different composition of phenolic substances ( $\mathrm{PPh}$; Mattivi et al. 2002, 2009). The corresponding wines present a wide spectrum of sensory features, including diverse astringency. This means diversified mouthfeel characteristics, as reported in the different Disciplinary Regulations of Italian wines (https://www.politicheagricole.it/). Some of these grapes are used for the production of well-known wines, such as Chianti or Barolo, which, in spite of their richness in tannin and intense mouthfeel, are appreciated by consumers and represent some of the best examples of Italian red wines (Piacenza et al. 2009, de Luca et al. 2019). At the end of the last century, there was a renaissance of Italian wines and, at the beginning of the 21 st century, a rising trend of propagation (a parameter evaluating the market interest in cultivars) was observed (Mannini 2004). The annual nursery production of graftings of Nebbiolo grew from 300000 to 1700 000, of Aglianico from 200000 to 1000000 and of Primitivo from 100000 to 1000000 . Nowadays, there is international interest in Italian cultivars, for example, some white and red cultivars, such as Sangiovese, Montepulciano, Barbera, Lambrusco and Nero d'Avola, are now grown in several Australian regions, such as the Riverina, Barossa Valley, McLaren Vale, Riverland and King Valley (Wine Australia 2019).

In view of such wide biodiversity, of the increase in high quality products and of the economic potential, it is quite surprising that the astringency of Italian red wines has never 
been systematically investigated and compared from a sensory point of view. Astringency is of great interest because it represents an intrinsic parameter of red wines that is strongly linked to their perceived quality (Sáenz-Navajas et al. 2011, and references therein). Several Italian wines have been studied in terms of the composition of their PPh. Data about their astringency as sensory parameters can only be recovered for some of them in a fragmentary way as a result of the impact of viticultural/oenological practices on the sensory profile (Boselli et al. 2004, Gerbi et al. 2006, Gambuti et al. 2009, Torchio et al. 2010, Pagliarini et al. 2013, Patrignani et al. 2017). Moreover, data on different cultivars are not comparable because of the methodological/ terminology differences (oenology, sensory techniques, phenolic analysis and vocabulary). This lack is one of the reasons why today it is not possible to identify specific astringency characters as one typical feature of any Italian wine.

Without this knowledge, winemakers are not supported either by the knowledge of the strengths and weaknesses of a specific grape cultivar, or by a shared sensory model. In the current market, the ability to associate a certain product to specific sensory attributes and territories is often a vehicle to commercial success. As a result, a more comprehensive characterisation of the astringency of Italian red wines would provide an opportunity to support/consolidate their international image, with positive commercial outcomes. Indeed, the commercial value of a wine is related to its intrinsic (e.g. sensory features) and extrinsic (e.g. geographical origin) characteristics and both are drivers for wine purchase and repurchase (Charters and Pettigrew 2007, Mueller et al. 2010, Sáenz-Navajas et al. 2016).

Among the many sensory characteristics of red wine, astringency is a key contribution to its perceived quality, although it is one of the most difficult sensory parameters to characterise and understand, due to the complex mechanisms underpinning its perception (Ployon et al. 2018). The wide complexity of this sensation has been arranged into a hierarchical vocabulary that includes seven categories and 33 terms (Gawel et al. 2000). Some of the seven categories are considered as 'unpleasant' (drying, harsh, unripe, dynamic, particulate) and some as 'pleasant' (complex, surface smoothness). Some authors (Vidal et al. 2017) spoke about of a 'polarisation of astringency' related to terms: those related to soft textures opposite to those related to rough textures and aggressiveness. Our consideration is that the less pleasant astringency sensations could positively impact the perceived quality when present in a wellbalanced wine. This appears to be supported by the fact that they are often present in premium wines suitable for long ageing. In contrast, those astringency sensations considered as pleasant could lead to less appreciated wines if not combined with other descriptors. Vidal et al. (2017) expected that both low and extremely high overall astringency intensity could be perceived as indicators of low quality in Tannat wines, being the typicity of this product linked to its astringency. We hypothesise that red wines can differ according to the balance between 'strong' and 'smooth' sensations defining their astringency. These two terms were already adopted to differentiate wines according to their astringency. Based on the characterisation of the intensity and sub-qualities of astringency, several groups of Tannat wines were identified: those characterised by intermediate astringency (described as dry, rough and mouth-coating); those eliciting smooth astringency characteristics (described as velvety, silky and suede); and those characterised by their strong astringency (described as hard, harsh and aggressive) (Vidal et al. 2017). Overall sensory intensity and persistence of red wines are positively correlated with astringency (Peynaud 1987), and therefore to tannin concentration (Gonzalo-Diago et al. 2013). A relationship between tannin concentration and wine allocation grade, that is related to market value, has also been described (Mercurio et al. 2010). Several authors studied the astringency of red wines through their sub-qualities (Green 1993, Gawel et al. 2001, Francis et al. 2002, Vidal et al. 2004, 2018, Ferrer-Gallego et al. 2014, Vidal et al. 2018), showing that astringency is not only complex but also a time-dependent sensation. Recent studies investigated the development of astringency sub-qualities over time by approaching this subject through temporal measurements (Guinard et al. 1986, Cadena et al. 2014, Vidal et al. 2016, Kang et al. 2019). They highlighted the importance of assessing astringency through an holistic chemosensory approach. It includes complementary information derived from static and/or temporal sensory assessments and chemical analysis. Some of these papers characterised the astringency features of a specific wine. The authors investigated astringency sub-qualities and the correlation between these sensory variables and chemical composition (Vidal et al. 2016).

In a similar manner, but for the first time on a large set of Italian red wines made $100 \%$ from native grape cultivars, this work mainly studied the astringency diversity of red wines from 11 cultivars representative of the Italy: Teroldego, Corvina, Raboso Piave, Nebbiolo, Sangiovese, Sagrantino, Montepulciano, Cannonau, Aglianico, Primitivo and Nerello Mascalese. These cultivars are used for the production of different wines labelled with Denomination of Origin Controlled (DOC) and Guaranteed Origin (DOCG).

To reach our goal the astringency sub-qualities of an initial set of 111 commercial wines were investigated by sensory analysis adopting a two-step analytical strategy composed of a sorting task and a sensory assessment through a numerical category scale. Multivariate statistical analyses, such as agglomerative hierarchical clustering (AHC) following multidimensional scaling (MDS), ANOVA, principal component analysis (PCA) and quadratic discriminant analysis (QDA) allowed a step-by-step definition of a reduced set of representative samples used to develop astringency profiles of single cultivars called 'astringency spectra'.

Furthermore, the wide diversity in PPh and astringency features of Italian red wines was exploited as an opportunity to investigate the correlation between specific in-mouth sensory variables (single astringency sub-qualities and tastes) and some aspects of chemical composition, particularly PPh measured with different methods, macromolecules and basic chemical analysis. Only some of these results are presented in this paper.

\section{Materials and methods}

\section{Wine samples}

One hundred and eleven Italian red wines, 100\% single cultivar, vinified in 2016 from 11 Italian grape cultivars, harvested in the corresponding main geographical areas of production (12 regions), were sampled from the commercial wineries where they were produced. For that reason, oenological parameters varied. The set of wines was composed of: 11 Teroldego Rotaliano (from Trentino-Alto Adige: TER), 
seven Corvina (from Veneto: COR), nine Raboso Piave (from Veneto: RAB), 13 Nebbiolo (from Piemonte: NEB), 19 Sangiovese (12 from Romagna: SAR; seven from Toscana: SAT), 10 Sagrantino di Montefalco (from Umbria: SAG), nine Montepulciano (from Abruzzo: MON), nine Cannonau (from Sardegna: CAN), ten Aglianico (from Campania: AGL), 11 Primitivo (from Puglia: PRI) and three Nerello Mascalese (from Sicilia: NER). Wines were fermented in stainless steel vats, at commercial scale, at wineries among the most representative in each area of production, and sampled before MLF and before wood ageing. All samples were protected with $50 \mathrm{mg} / \mathrm{L}$ of free $\mathrm{SO}_{2}$ before bottling; bottles were closed with a Select Green 500 cork type (Nomacorc, Rivesaltes, France) prior to storage at constant cellar temperature $\left(12 \pm 2^{\circ} \mathrm{C}\right)$ until analysis.

\section{Experiment 1: selection of wines}

This step was carried out to select the most representative wines belonging to each grape cultivar and to have first indication of the astringency features of the wines.

\section{Sorting task}

Panel The jury was composed of 14 people (seven males, seven females; 22-49 years) recruited from students and staff members of the Department of Agricultural Sciences, Division of Vine and Wine Sciences, University of Naples Federico II. They were selected on the basis of their interest, availability and ability in recognising oral stimuli. They all were expert wine tasters and had previous experience with sensory tests on wine. The study protocol has been approved by the Ethics Committee of University of Naples Federico II. All participants were volunteers and before participating in the study they signed an informed consent form defining the type of research, voluntary participation and agreement to sip and spit reference solutions and wines. All data were collected anonymously.

Panel training (phase 1: familiarisation with in-mouth sensations): In order to familiarise with the astringency vocabulary, judges were provided with a list of seven terms defining the diverse astringency categories (designated hereinafter as 'sub-qualities') of red wine as described at the first level of the mouthfeel wheel (Gawel et al. 2000): drying, harsh, unripe, dynamic, particulate, complex and surface smoothness. Assessors were provided with a sheet with the Italian translation of the definitions reported by Gawel et al. (2000). After the theoretical introduction, nine taste/mouthfeel references were presented to the jury in order to develop a consensual list of terms describing the oral sensations elicited by each standard (Tables 1,2 ). The same references were employed to exercise the jury to recognise and discriminate the different oral sensations and also to help in the application of terms consistently to the corresponding definitions. The references $(20 \mathrm{~mL}$ in covered disposable plastic cups) were presented in water and in red table wine. A 5-year-old Pinot Noir was used as reference for the surface smoothness (Cliff et al. 2007). Tannic acid and four commercial tannin-based products were used as sensory references for astringency and its sub-qualities (Table 1). The appropriate concentration was chosen through preliminary intra-laboratory tests. The association of the terms to these references was obtained by asking the assessors to take a sip (15 mL), to move the sample (15 s) while wetting the whole mouth and then record the most intense sensations. Only descriptors cited at least by $85 \%$ of the jury were matched to the terms as reported in Table 1 and considered as consensually associated to the corresponding sensory reference.
At the end of each tasting session the perceived sensations were discussed in order to agree on a common definition (Table 2). Relationships and redundancies among the terms were discussed. At the end of the training, it was consensually decided that the terms 'surface smoothness' and 'particulate' were to be labelled as 'velvet' and 'powdery' astringent sensations, respectively. To help in memorisation and in consistent use of terms, as well as to prevent overlapping, a consensus was found on simplified descriptions for the terms. They were schematised (Table 2) and a sheet with the simplified descriptions was attached to the wall of each booth during all the subsequent sessions. The first session was considered introductory, so that data collected only from the second and third training sessions were employed to calculate the frequency of citations for matching standards with descriptor/s and to test panellist performance.

Panel training (phase 2: familiarisation with sorting): Assessors were introduced to the sorting procedure. For this purpose, eight red wines (30 mL in covered ISO wine glasses) from different cultivars were presented. Judges were asked to introduce the sample into their mouth, focus on the perception of astringency and sort samples according to their similarity in astringency sub-qualities on which they were trained. Panellists were asked to label each group with the dominant sub-quality/s perceived among the seven on which they were trained. Judges were allowed to make as many groups of similar samples as possible and groups of single samples were permitted. Between two samples, assessors were asked to rinse the mouth by drinking bottled still water (Evian), to eat some apple slices, then drink a second time and finally wait at least $30 \mathrm{~s}$ before the subsequent evaluation. At the end, it was checked if the definitions of terms needed to be refined in this context of wines representative of the sample set under investigation. After discussion, no changes were made and the consensus was confirmed on all the definitions reported in Table 2. During the discussion judges were also asked about the roughness/aggressiveness of the different sensations: drying, harsh, dynamic, unripe and particulate were mostly perceived as strong/aggressive while complex and velvet as smooth/not aggressive.

Samples analysis. Wines were evaluated by sorting according to an intra-cultivar experimental design meaning that all the wines from a given cultivar were sorted in the same session. In this way, an intra-cultivar sorting was performed in order to investigate similarities and dissimilarities among wines belonging to the same cultivar (from seven Corvina to $13 \mathrm{Neb}$ biolo). Due to the limited number of samples (only three), Nerello Mascalese was not included in this first intra-cultivar experimental step so that a total of 108 samples were analysed by sorting. Judges attended 11 sessions corresponding to the number of single cultivar wines (Sangiovese wines were divided into two sessions according to geographical origin). The evaluation procedure was the same of the training. Assessors were asked to group samples according to the similarity in their astringency sub-qualities and label the groups. Thirteen samples, corresponding to the maximum number of wines sampled within a single cultivar wine, were evaluated during each session. When less than 13 wines were available, 'fake' samples were obtained by blending available wines of the same cultivar; data about these samples were not considered. Samples $(30 \mathrm{~mL})$ were presented according to a randomised arrangement in covered ISO approved wine glasses labelled with three-digit random codes. All wines were served at room temperature $\left(21 \pm 1^{\circ} \mathrm{C}\right)$ and were evaluated in individual booths. 
Table 1. References and corresponding consensual descriptors used to train the assessors in recognising and distinguishing among the different in-mouth sensations (tastes and astringency sub-qualities).

\begin{tabular}{|c|c|c|c|}
\hline References & $\begin{array}{c}\text { Concentration } \\
(\mathrm{g} / \mathrm{L}) \dagger\end{array}$ & Descriptors $¥ \S$ & Producers \\
\hline Fructose & 2 & Sweet & J.T. Baker (Avantor; Radnor, PA, USA) \\
\hline Tartaric Acid & 4 & Sour & $\begin{array}{l}\text { Chem-Lab (Eernegem, } \\
\text { West-Vlaanderen, Belgium) }\end{array}$ \\
\hline Caffeine & 2 & Bitter & ACEF (Piacenza, Italy) \\
\hline Tannic acid & 2 & Astringt & J.T. Baker (Avantor; Radnor, PA, USA) \\
\hline $\begin{array}{l}\text { Tannin VR colour (catechin and ellagic } \\
\text { tannins formulation) }\end{array}$ & 4 & Drying and Harsh & Laffort (Bordeaux, France) \\
\hline $\begin{array}{l}\text { Tannin VR grape (proanthocyanidic } \\
\text { tannins extracted from grape skin and } \\
\text { seeds) }\end{array}$ & 2 & $\begin{array}{l}\text { Particulate (as Powdery) and } \\
\text { Unripe }\end{array}$ & Laffort (Bordeaux, France) \\
\hline Tannin plus (tannins formulation) & 4 & Complex and Drying & Laffort (Bordeaux, France) \\
\hline $\begin{array}{l}\text { Tannin galalcool (gallic tannins from } \\
\text { gallnuts in granulated form) }\end{array}$ & 2 & Unripe & Laffort (Bordeaux, France) \\
\hline Red wine (Pinot Noir 5 years old) & - & $\begin{array}{l}\text { Surface Smoothness (as } \\
\text { Velvet) }\end{array}$ & $\begin{array}{l}\text { St. Michael Eppan (Trentino Alto Adige, } \\
\text { Italy) }\end{array}$ \\
\hline
\end{tabular}

$\dagger$ Both in distilled water and in table red wine $(\mathrm{pH}=3.2$; ethanol $=12.5 \% \mathrm{v} / \mathrm{v}$; titratable acidity $=7.7 \mathrm{~g}$ tartaric acid/L; residual sugars $=1.5 \mathrm{~g} / \mathrm{L}$; total anthocyanins $=36 \mathrm{mg} / \mathrm{L} ; \mathrm{BSA}$ reactive tannins $=112 \mathrm{mg} / \mathrm{L}$ ). \#Agreed definitions are reported in Table 2 . §Consensual association frequency $\geq 85 \%$.

\section{Experiment 2: sensory assessment of wines}

The aim of this step was to obtain a sensory descriptive assessment of in-mouth features (tastes and astringency sub-qualities) of a reduced number of wine samples selected as the most representative within each single cultivar wine.

Wine samples. A set of 77 wines was analysed: 74 (five SAT and five SAR; eight TER; seven NEB, RAB, CAN, SAG, MON, COR, PRI and AGL) were selected according to the results of the sorting and three were the Nerello Mascalese (NER) wines.

\section{Descriptive analysis}

Panel training The nine taste/mouthfeel references listed in Table 1 were presented to the jury in order to train them to score the intensity of different in-mouth sensations on the following numerical category scale: $1=$ very low, $2=$ low, $3=$ medium, $4=$ high, and 5 = very high, with half values allowed. Materials and serving conditions were the same as above.

In order to familiarise the jury with the evaluation procedure, nine samples (three each in duplicate of RAB, SAG and TER) were tested prior to the analytical sessions, as a run-through. The procedure and the conditions were the same as described previously. Data were employed to test the performance of panellists.

Sample analysis The 77 wines were analysed in terms of astringency and taste by using the terms listed in Table 2, and by scoring the intensity of the perceived descriptors on the scale applied during the training.

The sensory assessment was performed according to an inter-cultivar experimental design meaning that 11 wines corresponding to the 11 single cultivar wines were evaluated during each of the seven sessions. Each sample $(25 \mathrm{~mL})$ was served as previously described. Panellists were asked to taste each sample by focusing on astringency by paying attention not only to the most intense sensation but also to that/those catching their attention the most during the tasting time, describing and scoring the diverse sensations by using the seven terms corresponding to the seven sub-qualities, and finally by scoring taste sensations (sweet, acid, bitter). Judges were informed that,

Table 2. Definitions of the terms considered to assess astringency.

\begin{tabular}{|c|c|c|}
\hline Terms & Agreed definitions & Simplified definitions \\
\hline Astringency ${ }^{\dagger}$ & $\begin{array}{l}\text { Oral tactile sensation mainly } \\
\text { characterised by dryness and } \\
\text { roughness }\end{array}$ & \\
\hline Drying $\ddagger$ & $\begin{array}{l}\text { Lack of lubrication and dehydration } \\
\text { feeling in the mouth }\end{array}$ & No lubrication + dehydration \\
\hline Harsh $\ddagger$ & $\begin{array}{l}\text { Unbalanced in-mouth sensation of } \\
\text { dryness, roughness (irregularities and } \\
\text { lack of smoothness) and bitterness }\end{array}$ & $\begin{array}{l}\text { Astringency + roughness + bitterness } \\
\quad(\text { combined and aggressive/excessive) }\end{array}$ \\
\hline Dynamic $\ddagger$ & $\begin{array}{l}\text { Sensations impacting on fluidity of oral } \\
\text { movement }\end{array}$ & Lack of fluidity \\
\hline Particulate (as powdery) $\neq$ & $\begin{array}{l}\text { Oral sensation associated with the touch } \\
\text { of powdery matter }\end{array}$ & Powdery at touch \\
\hline Unripe & $\begin{array}{l}\text { Unbalanced in-mouth sensation of } \\
\text { astringency, sourness and green } \\
\text { aroma }\end{array}$ & $\begin{array}{l}\text { Astringency }+ \text { acid }+ \text { herbaceous } \\
\quad(\text { combined and aggressive/excessive })\end{array}$ \\
\hline Surface smoothness (as velvet) $\ddagger$ & $\begin{array}{l}\text { Oral texture sensation associated with } \\
\text { the touch of velvet }\end{array}$ & Velvet at touch \\
\hline Complex $\ddagger$ & $\begin{array}{l}\text { Balanced in-mouth sensation of smooth } \\
\text { astringency, acidity and retronasal } \\
\text { stimulation }\end{array}$ & $\begin{array}{l}\text { Astringent }+ \text { acid }+ \text { flavoured (combined } \\
\text { and not aggressive/excessive) }\end{array}$ \\
\hline
\end{tabular}

$\dagger$ As defined by Vidal et al. (2016). ¥Agreed definitions elaborated by starting from those reported by Gawel et al. (2000). 
based on data from training sessions, at least three of the astringency descriptors were expected to be higher than the minimum value on the scale, but no limitations were imposed. Judges were asked to rinse their mouth between two samples.

Chemical analysis of wines. Ethanol, reducing sugars, volatile acidity (VA) and TA were measured according to OIV methods (OIV 2015). pH was determined by potentiometry (InoLab 730 pH meter, WTW, Weilheim in Oberbayern, Germany). Total phenols were measured by Folin-Ciocalteu assay (Singleton et al. 1999). The concentration of proanthocyanidins was determined after acid hydrolysis with warming (Bate-Smith reaction) using a ferrous salt $\left(\mathrm{FeSO}_{4}\right.$ ) as catalyst (Di Stefano et al. 1989, Torchio et al. 2010). Analyses were in triplicate.

Data analysis. In order to visualise groupings of wine samples due to astringency similarities analysed by sorting, MDS analysis followed by AHC analysis were performed and the co-occurrence similarity matrices were considered. As previously reported (Sáenz-Navajas et al. 2012, and references therein), for each assessor, results were organised under an individual similarity matrix (wines $\mathrm{x}$ wines): 1 corresponded to two wines put into the same group while 0 was for two wines put in different groups. The sum of the individual matrices across judges was merged into a co-occurrence matrix representing the global similarity matrix where the higher the number the higher the similarity between samples. This method assumes that samples frequently grouped together were perceived as more similar compared to those sorted into different groups. The proximity matrix (Euclidean distances between the products) was the base for the MDS analysis (SMACOF algorithm). The quality of fit was measured by the stress value (from $0=$ perfect fit to $1=$ worst fit). As previously reported and applied, a value bellow 0.2 can be considered as a good agreement between the initial and final configurations, so that this stress value was adopted as a criterion to select the number of dimensions for the MDS spaces. Coordinates of samples in the retained MDS configurations were submitted to a HCA with the ward criterion. We applied the automatic truncation option, which is based on the entropy and tries to create homogeneous groups. Agglomerative hierarchical clustering was helpful for the interpretation of MDS maps allowing the identification of wines belonging to each cluster. We arbitrary decided to select at least seven samples of each single cultivar wine. In this way at least $50 \%$ of each single cultivar sample set was selected, indeed the most numerous set of wines was composed of 13 NEB. Data from the descriptive sensory assessment were analysed by one-way ANOVA (wine was the factor and judges were considered as random

Table 3. Oenological parameters determined in the 111 single cultivar Italian red wines.

\begin{tabular}{lccc}
\hline Parameter & Mean & Minimum & Maximum \\
\hline Ethanol (\% v/v) & 13.9 & 11.4 & 16.6 \\
Reducing sugars (g/L) & 2.6 & 1.0 & 20.1 \\
TA (g tartaric acid/L) & 5.7 & 4.0 & 10.0 \\
$\mathrm{pH} \quad$ & 3.6 & 3.1 & 4.1 \\
Total phenols & 2341 & 704 & 5449 \\
$\quad \begin{array}{l}\text { (Folin-Ciocalteu) [mg } \\
\quad(+) \text {-catechin/L] }\end{array}$ & & & \\
$\begin{array}{l}\text { Proanthocyanidins (mg } \\
\text { cyanidin chloride/L) }\end{array}$ & 3373 & 628 & 6312 \\
\hline
\end{tabular}

factor), and the mean intensity for each astringency subquality was compared (intra- and inter-cultivar) by a Tukey post-hoc test $(P<0.05)$.

A PCA was applied to the original in-mouth variables (astringency sub-qualities and tastes) constituted by the sensory scores. Sensory data referring to astringency subqualities were also computed as the geometric mean of frequency and mean intensity [mean sensory modified frequency $(\mathrm{MF})]$ as described by Dravnieks (1982): $\mathrm{MF}=\left(F^{*}\right.$ $I)^{1 / 2}$, where $F$ is the frequency of citation expressed as a proportion of the maximum frequency of citation (i.e. total number of judges) and $I$ is the mean intensity expressed as a proportion of the maximum rate.

Quadratic discriminant analysis was used to classify the wines assuming the cultivar as a qualitative dependent variable and MF of the astringency sub-qualities as quantitative explanatory variables (inequality of covariance matrices tested by Box test; Jarque-Bera normality test; $\alpha=0.05$ ). The classes weight correction was applied because the number of observations for the various classes for the dependent variables was not uniform. The classification functions were used to determine which class (cultivar) an observation (wine) is to be assigned to using values taken for the various explanatory variables. An observation was than assigned to the class with the highest classification function. Only wines that, after cross-validation, were well-classified to the corresponding grape cultivar, were further considered to develop single cultivar astringency patterns. In order to satisfy the assumption that the number of explanatory variables (six) was lower than each sample size, NER samples (only three) were not included in the discriminant analysis.

Pearson correlation analysis $(P<0.05)$ was applied across the whole set of wines (sample size $=77$ ) for the computation of correlations between the intensity of astringency sub-qualities and in-mouth sensory variables or chemical parameters.

Performance of the trained judges was tested by threeway ANOVA (Tukey, $P<0.05$ ) with interactions of assessor*session, assessor*sample, sample*session (Vidal et al. 2016).

Data were processed with XLStat (version 2018.7), an add-in software package for Microsoft EXCEL (Addinsoft, Paris, France).

\section{Results}

\section{Selection of wines}

Basic compositional data of the wine samples are shown in Table 3. The ranges of these parameters were large, thus astringency differences were expected in the set of sampled wines. Data from the wines sorted according to astringency similarities were analysed by AHC after MDS. According to the dendrograms (Figure S1), within each single cultivar wine, samples resulted clustered into three groups represented on three (Sangiovese, Sagrantino, Raboso, Primitivo, Nebbiolo, Corvina) or four (Aglianico, Montepulciano, Cannonau, Teroldego) dimensions on the MDS spaces (not shown).

From these results, we selected samples from each wine type according to the following criteria: the most similar couple of wines, couples including the central object of each cluster, at least three wines from the most homogeneous cluster (lowest within-class variable) when larger than two objects, at least one sample (central object) belonging to each cluster (excluding clusters composed of one sample). 
When necessary, distances from the MDS output were adopted as additional criteria to select at least $50 \%$ of samples from each cultivar. In this manner we reduced the number of samples belonging to each mono-cultivar wine by preserving the representativeness in terms of intracultivar similarities and diversities. The final set of 77 selected wines was then composed of: ten Sangiovese (five each from Romagna and from Toscana), eight Teroldego, seven Nebbiolo, Aglianico, Primitivo, Montepulciano, Cannonau, Raboso Piave, Corvina and Sagrantino, plus three Nerello Mascalese.

\section{Description and discrimination of wines}

Each astringency sub-quality of the 11 single cultivar wines was compared (Figure 1) and, several differences emerged for six out of the seven sub-qualities. According to the significance $(P<0.05)$ reported on the top of each box, only some of these differences were significant.

Three main levels of drying intensity were identified: Nebbiolo and Sagrantino showed the highest mean intensity, followed by Raboso, Primitivo and Nerello Mascalese and then by Corvina. Two further intermediate levels corresponded to the drying intensity of the other wines. Sagrantino and Corvina wines represented the highest and lowest values, respectively, of the harsh intensity. Some significant differences were detected among the other wines, except for Sangiovese and Nerello.

For unripe, the highest mean intensity was associated with Raboso, in contrast to Sangiovese, Nebbiolo and Nerello which were less unripe and significantly different from that of Corvina, Montepulciano was not different according to its unripe character. Astringency of Sagrantino was perceived as the most dynamic while Teroldego, Primitivo, Montepulciano and Corvina was less so. For dynamic no differences emerged for all the other wines. Cannonau and Primitivo were different from Nebbiolo which was the less complex. Corvina was opposite to Nebbiolo with the highest and the lowest values for surface smoothness, respectively. Raboso and Primitivo were more velvet than Nebbiolo, while Sangiovese less than Corvina. Finally, the sub-quality particulate for the 11 single cultivar wines was not significantly different, and therefore, this sub-quality was not considered for the subsequent analyses.

Figure 2 shows the PCA where all in-mouth sensory variables (a) and observations (b) were plotted on the first two components representing $58.81 \%$ of the variance. The astringency sub-qualities and the bitter taste are mostly represented on $\mathrm{PCl}$, while the contrast between acid and sweet tastes is represented on $\mathrm{PC} 2$. The variables that positively correlated $(P<0.0001)$ to each other are: dynamic with drying $\left(R^{2}=0.565\right)$, harsh with bitter $\left(R^{2}=0.771\right)$, acid with unripe $\left(R^{2}=0.593\right)$, surface smoothness with complex and sweet $\left(R^{2}=0.283\right.$ and $R^{2}=0.256$, respectively). Drying and dynamic were negatively correlated $(P<0.0001)$ to surface smoothness $\left(R^{2}=-0.642\right.$ and $R^{2}=-0.463$, respectively). Compared to unripe, harsh showed an opposite correlation to acid taste $\left(R^{2}=-0.577\right)$. Most of the Sangiovese, Nebbiolo and Sagrantino wines showed the largest squared cosines to positive values of the first factor, where the variables drying and dynamic, harsh and bitter are well projected. On the other side of the first factor, in the space where the best represented variables are acid, surface smoothness and unripe, different wines showed the largest squared cosines, mainly Corvina and Raboso. Along the second factor, some Raboso, Aglianico and Montepulciano wines were
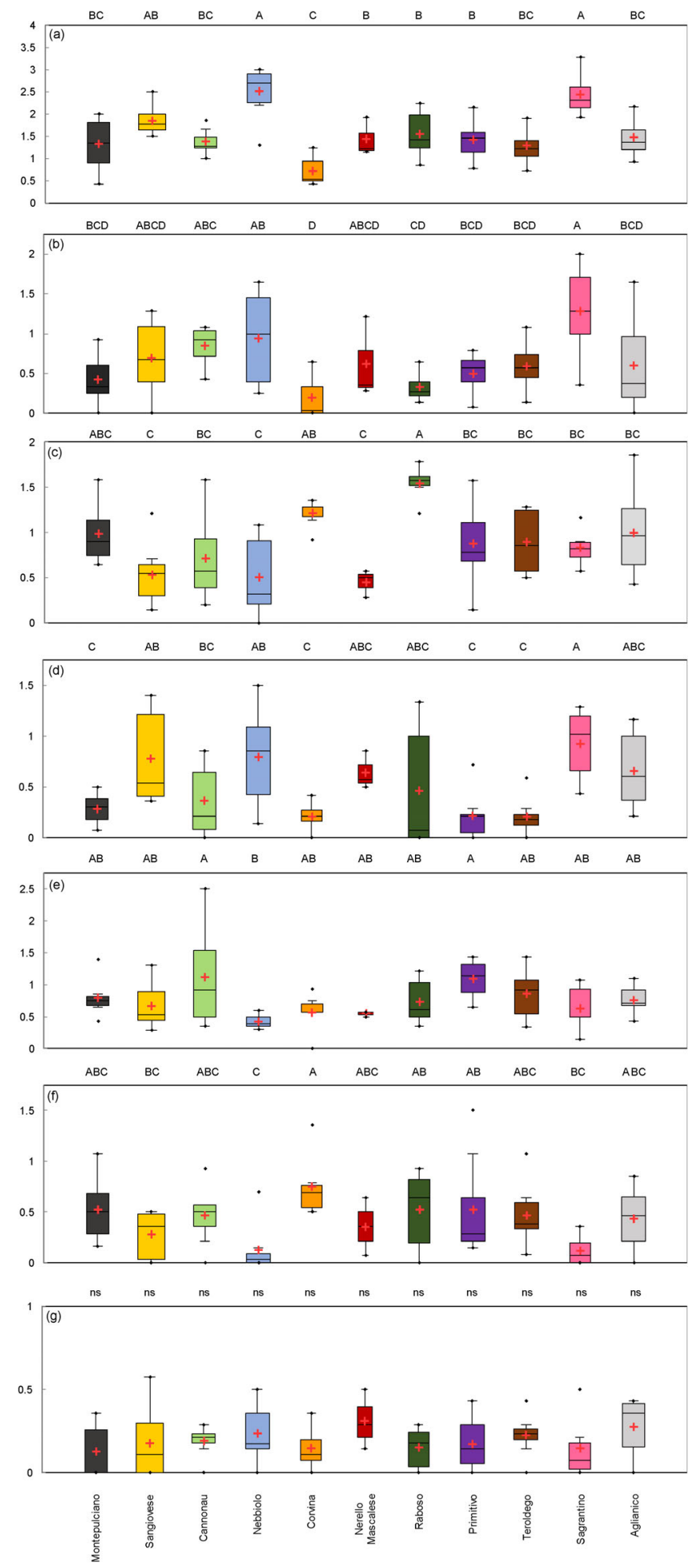

Figure 1. Box-plots describing inter-cultivar diversity of each astringency sub-quality in the 11 single cultivar Italian red wines investigated [means (+); central horizontal bars: medians; lower/upper limit of the box: first/third quartile; points above/below the whiskers' upper/lower bounds: outliers; box-plot's horizontal width: no statistical meaning]. Letters reported on the top of each box-plot refer to significant differences tested by ANOVA (Tukey, $P<0.05$; drying: $F=11.254, P<0.0001$; harsh: $F=4.655, P<0.0001$; unripe: $F=5.594, P<0.0001$; complex: $F=3.346 ; P<0.0001$; dynamic: $F=5.943, P<0.0001$; particulate: $F=0.562, P=0.846$; surface smoothness: $F=4.209, P<0.0001$ ).

linked to the acid taste, opposite to Cannonau, Primitivo and Teroldego which were linked to the sweet. A wide intra-cultivar diversity results for Aglianico wines, which occupy the most diversified positions in the PCA space. 

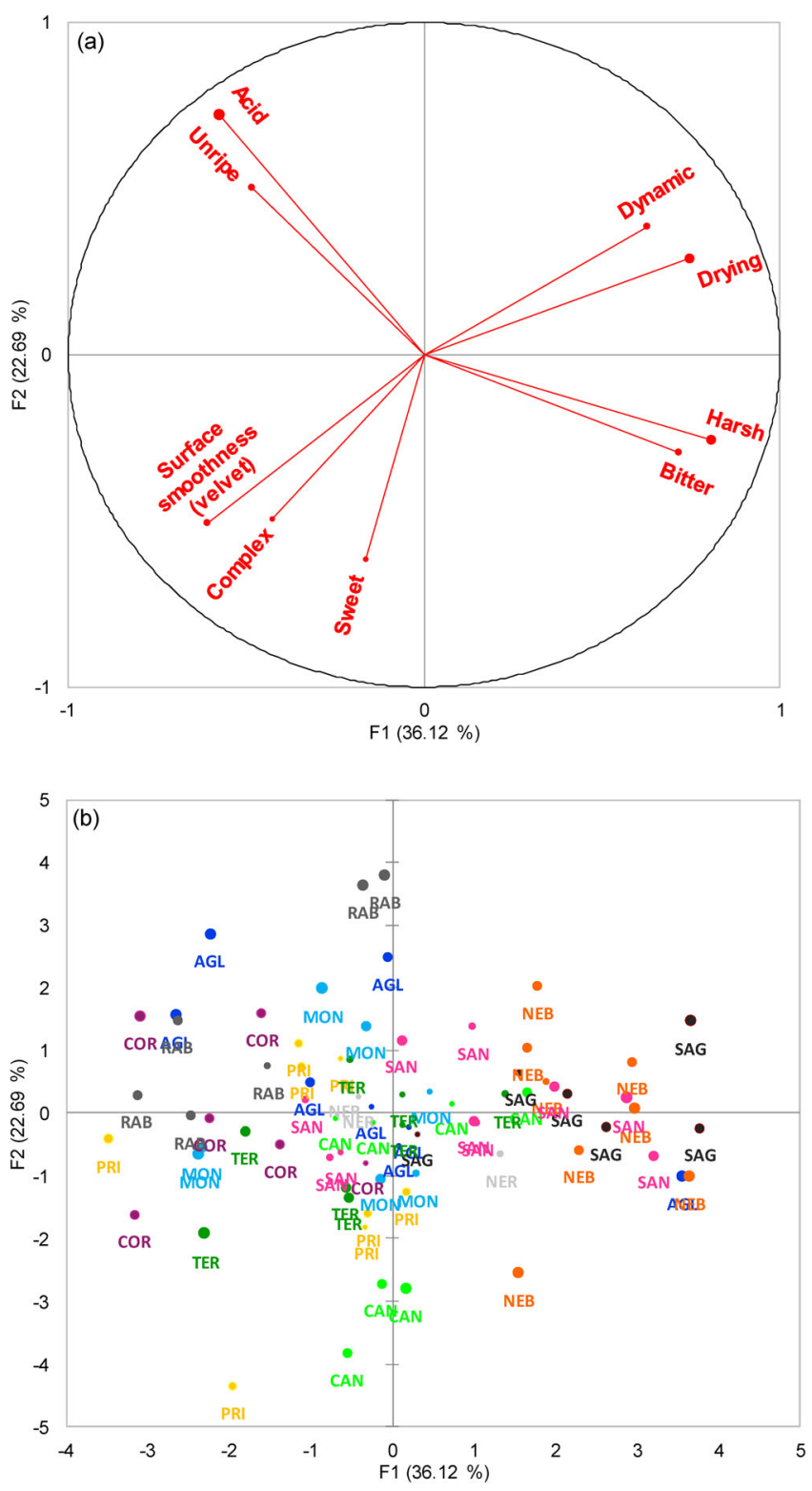

Figure 2. Principal component analysis (PCA) plots, (a) variables and (b) observations calculated on intensity scores (AGL, Aglianico; CAN, Cannonau; COR, Corvina; MON, Montepulciano; NEB, Nebbiolo; PRI, Primitivo; RAB, Raboso Piave; SAG, Sagrantino; SAN, Sangiovese; TER, Teroldego).

Figure 3 shows the output of the QDA. The goal was to test if the single cultivar wines could be discriminated and clustered only according to their astringency sub-qualities (MF values). As previously applied on olfactory and inmouth descriptors (Lelièvre et al. 2008), the MF method was applied because it takes into account both types of values produced by assessors: the frequency of citation of a sensory term and the intensity assigned to it. In this way we properly considered cases in which a term has been used frequently but with low scores, and cases in which the same descriptor has been poorly cited but with high scores. The loading plot (Figure 3a) represents the contribution of each astringency sub-quality to the discrimination. On the first two factors $82.09 \%$ of the variance is represented: Fl carried the majority of the differentiation of the samples $(65.57 \%)$ with the sub-qualities dynamic, drying and harsh opposite to unripe and surface smoothness. The first three correlated on the positive semi-axis $(R=0.616, R=0.888$,
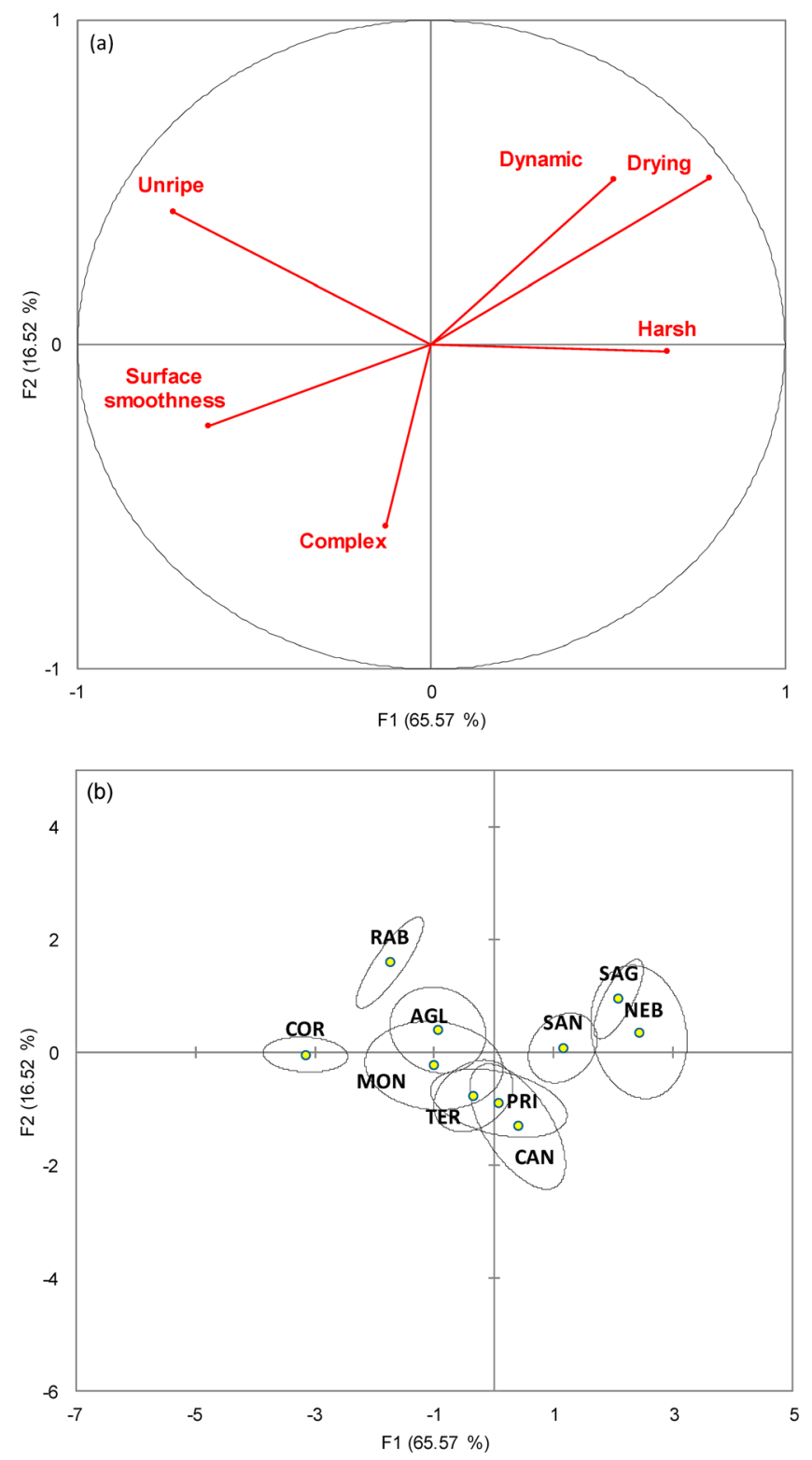

Figure 3. Quadratic discriminant analysis computed using mean sensory modified frequency of astringency sub-qualities (drying, harsh, unripe, dynamic, complex and surface smoothness) as quantitative explanatory variables. (a) Vectors show astringency sub-qualities contributing to the overall variance between single cultivar wines. (b) Ellipses show 95\% confidence intervals for each single cultivar wine around the corresponding centroids (AGL, Aglianico; CAN, Cannonau; COR, Corvina; MON, Montepulciano; NEB, Nebbiolo; PRI, Primitivo; RAB, Raboso Piave; SAG, Sagrantino; SAN, Sangiovese; TER, Teroldego).

$R=0.767$, respectively), while the latter two on the negative semi-axis $(R=0.830, R=0.731$, respectively). The F2 was negatively correlated to complex. The representation of centroids and corresponding confidence ellipses on the factor axes (Figure $3 \mathrm{~b}$ ) showed that some single cultivar wines were more discriminable than others according to their astringency sub-qualities. Raboso and Corvina were mainly distinguishable for their unripe astringency, with a velvet character in the latter. Nebbiolo, Sagrantino and Sangiovese were mostly discriminated for their strong astringency components (drying, dynamic, harsh) while the remaining wines were mostly in the middle of the map showing overlapping confidence ellipses.

For each observation (wine sample), the probability of belonging to each group (single cultivar wine) was 
computed, and each wine was reclassified into the group for which the probability of belonging was the greatest. According to the confusion matrix, $88 \%$ of the wines were correctly reclassified: Corvina, Raboso, Nebbiolo, Sagrantino and Sangiovese samples were $100 \%$ correctly matched to the corresponding cultivar, followed by Cannonau and Primitivo $(85.71 \%)$, Teroldego $(75.00 \%)$, Aglianico (71.43\%) and Montepulciano (57.14\%).

Only the wines correctly reclassified were taken into account to develop, for each of the corresponding ten single cultivar wines, a graphical representation of their astringency features. For each single cultivar wine, the astringency sub-quality with the highest MF (mean value over the wines retained in the analysis) was considered as 100 and the MFs of the five remaining sub-qualities were normalised with respect to it. In this manner, as for a typical mass spectrum, we obtained a histogram corresponding to the 'astringency spectrum' of a given single cultivar wine where, the six sub-qualities were conceived as 'fragments' of the whole astringency of that wine (Figure 4). The abundance of each astringency sub-quality was plotted by computing its occurrence relative to the most important subquality detected in that single cultivar wine. In this way we obtained normalised profiles that allowed a comparison of the average relative contribution of each sub-quality to the astringency, within each of the diverse single cultivar wines. The patterns resulted different from each other, eight wines were dominated by the drying astringency (Figure $4 a-f, h, i)$, two by the complex (Figure $4 \mathrm{l}, \mathrm{m}$ ) and one by the unripe (Figure $4 \mathrm{~g}$ ).

\section{Correlations}

Pearson correlations $(P<0.05)$ were computed to test, across the different single cultivar wines, the association between the variables describing in-mouth sensations: astringency sub-quality, A; taste sensation, T; and a set of chemical variables concerning $\mathrm{PPh}$, and wine base chemical composition (BCP) (mean of triplicate analyses). Figure 5 represents the map of the correlations (correlation coefficients were detailed as Table S1). At least one significant correlation was found for each variable and in most cases with a $P$-value $<0.0001$.

The PPh variables, total phenols and proanthocyanidins, were: (i) highly $(P<0.0001)$ positively correlated to drying $\left(R^{2}=0.558\right.$ and 0.708 , respectively), harsh $\left(R^{2}=0.479\right.$ and $0.475)$ and dynamic $\left(R^{2}=0.468\right.$ and 0.583$)$; (ii) weakly negatively correlated to unripe $\left(R^{2}=0.304\right.$ and 0.365$)$ and surface smoothness $\left(R^{2}=-0.408\right.$ and -0.433$)$; and (iii) not correlated to complex. Among sweet, acid and bitter tastes, only the two latter showed weak correlation with PPh parameters. Also some correlations between BCP and inmouth variables emerged but only those between $\mathrm{pH}$ and acidity $\left(R^{2}=-0.562\right)$ or bitterness $\left(R^{2}=0.497\right)$ were the strongest $(P<0.0001)$. The VA positively correlated with harsh $\left(R^{2}=0.444\right)$, bitter $\left(R^{2}=0.405\right)$ and drying $\left(R^{2}=0.311\right)$, and negatively to acid $\left(R^{2}=-0.290\right)$ and complex $\left(R^{2}=-0.265\right)$.

\section{Discussion}

\section{Description and discrimination of wines}

From this study we obtained sensory profiles describing the balance among astringent sensations elicited by an extensive sample set of single cultivar Italian red wines representing different styles of astringency. Several studies focusing on
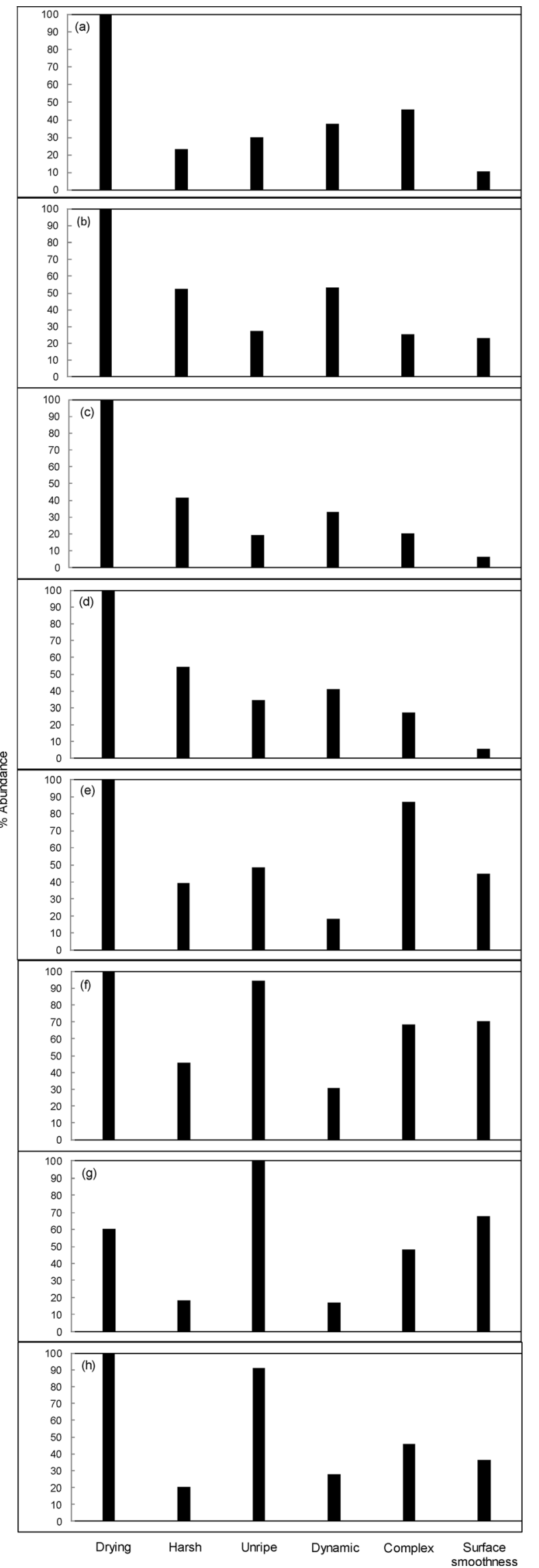

Figure 4. 'Astringency spectra' developed for the single cultivar wines. (a) Sangiovese Toscana (SAT); (b) Sangiovese Romagna (SAR); (c) Nebbiolo (NEB); (d) Sagrantino (SAG); (e) Primitivo (PRI); (f) Montepulciano (MON); (g) Corvina (COR); (h) Raboso (RAB); (i) Aglianico (AGL); (j) Teroldego (TER); (k) Cannonau (CAN). 


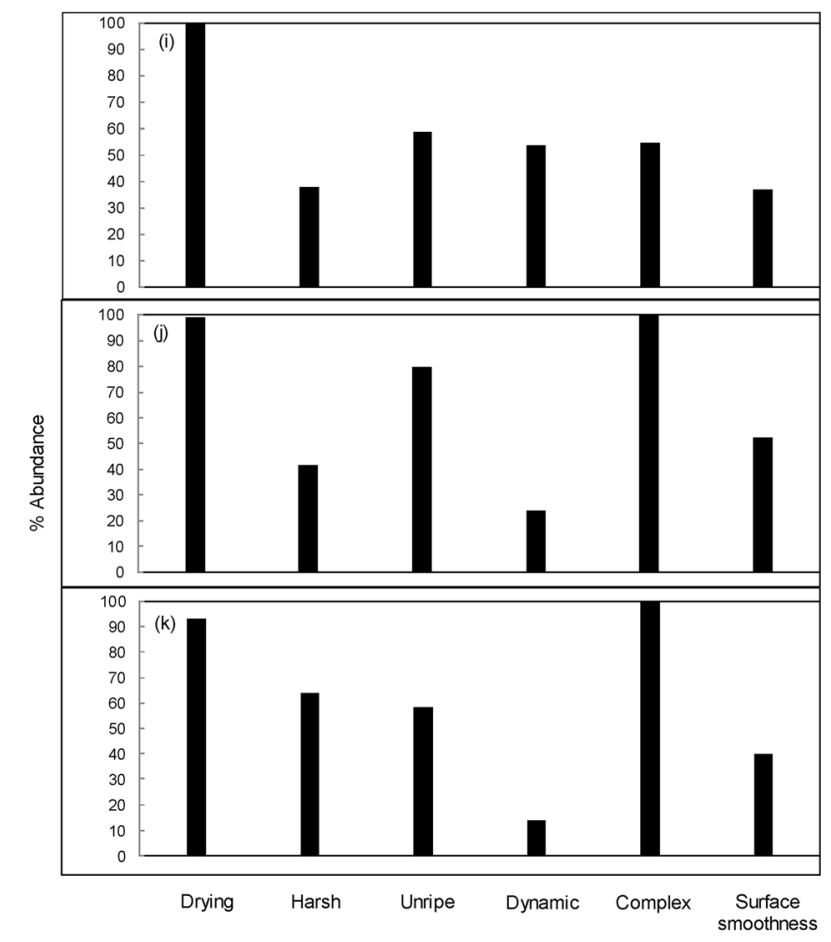

Figure NaN. Continued

molecules known to be responsible for astringency have been conducted on Italian red wines/grapes (Mattivi et al. 2002, 2009) but, for the first time, the astringency diversity of Italian red wines has been systematically investigated and compared from a sensory perspective. As in previous studies on red wine astringency (Ferrer-Gallego et al. 2016, Vidal et al. 2016), this study was carried out in full perceptual conditions (all senses). This allowed the assessment of wine astringency under conditions similar to that occurring during wine consumption, when cross-modal sensory interactions can occur. By merging the results reported through this study it appears possible to state that even if an intracultivar diversity was detected, it was possible to identify a pattern of astringency features common to wines from a given grape cultivar. Indeed, referring to the box-plots (Figure 1), we could gather that the shorter the box, the lower the variability of that sub-quality in that wine type. This suggests a wine feature that has been perceived in a similar manner in all samples by all judges, and therefore likely to be linkable to the grape cultivar (e.g. strong unripe in Raboso and Corvina; very low dynamic in Teroldego, Corvina and Primitivo; absence of velvet character in Nebbiolo and Sagrantino). Such a result suggests that these astringency features could be linked to the grape cultivar.

The detection of single wines or groups with different levels of intensity for the various astringency sub-qualities testifies the inter-varietal astringency diversity. The 11 single cultivar wines were differentiated at least for three different levels of intensity for drying, two for harsh, unripe, dynamic, complex and velvet, while none for particulate. This indicates that judges showed a good understanding of what the different sub-qualities are, and that the 11 wines were distinguishable mostly according to the drying astringency sensation. The lack of a significant difference among wines for the term particulate (here intended as powdery) is in agreement with latest results obtained by applying the modified progressive profiling, a dynamic sensory method (Kang et al. 2019). The study reports that, differently from the other sub-qualities, the graininess, which was defined as a sensation of particulate matter on the mouth surface, resulted in a variable not useful to discriminate the astringency of 13 red wines.

The PCA performed on sensory intensities highlighted correlations between the six astringency sub-qualities and tastes (Figure 2). Some of these correlations (e.g. harsh and bitter, unripe and acid) suggest that judges correctly used the sub-qualities descriptors according to their definitions (Table 2). Taste variables occupied three distinct parts on the map. Also the six astringency sub-qualities were well projected on three distinct areas of the chart, each of them close to a taste variable. The unripe astringency was not correlated to any of the other sub-qualities, suggesting a different 'nature' of this sub-quality compared to the others. The PCA found that in-mouth sensations of Sagrantino, Nebbiolo and Sangiovese were perceived as similar, and mainly
Scale of the correlation coefficients

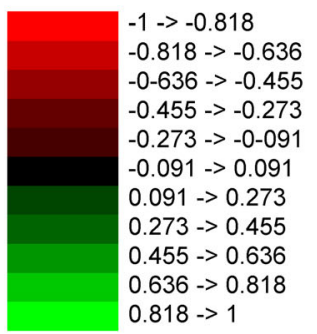

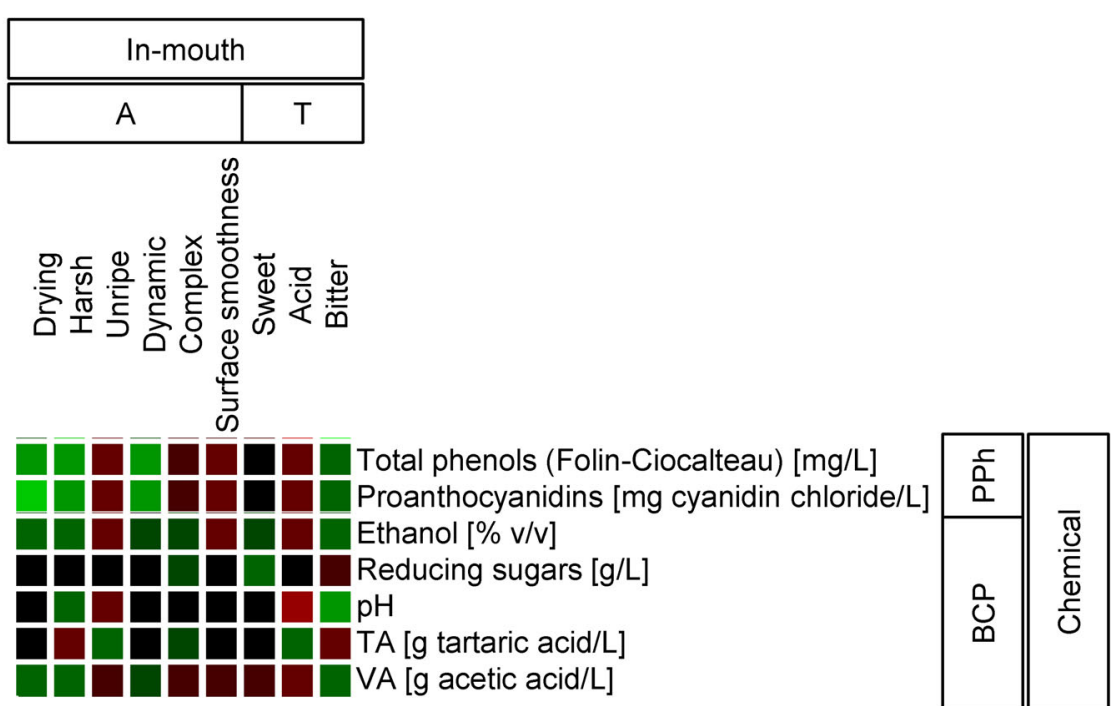

Figure 5. Map of the correlations (Pearson) between in-mouth and chemical variables (A: astringency sub-qualities; T: tastes; PPh: phenolic substances; BCP: basic chemical parameters). Corresponding $P$-values are reported in Table S1. 
associated to strong astringency sub-qualities and bitter taste. The other wines were spread on the opposite side of the chart sharing some common characteristics. The outputs of the QDA (Figure 3) showed that only some of the 11 single cultivar wines were discriminable from others due to their astringency features. Corvina and Raboso were discriminable from the other single cultivar wines and similar to each other, mostly for their unripe character. The discriminability of Nebbiolo, Sagrantino and Sangiovese was highlighted. All the other wines were not well discriminable according to their astringency features. This could be due to a higher degree of intra-varietal variability or to a more balanced contribution of the diverse astringency sensations. Each single cultivar wine showed a unique pattern among the six astringency sub-qualities. The astringency spectrum (Figure 4 ) of the single cultivar wines that were $100 \%$ correctly reclassified (Corvina, Raboso, Nebbiolo, Sagrantino and Sangiovese) can be considered as more reliable than the others. The future assessment of a larger and new distinct representative set of the same single cultivar wines could be useful to validate the astringency profiles that were developed in this study. According to the dominant sub-quality, three groups of wines can be distinguished: those dominated by the drying character, two dominated by the complex sub-quality and the one dominated by an unripe astringency, namely Corvina. The astringency spectrum of Sagrantino (Figure 4d) and Sangiovese from Romagna (Figure 4b) was similar for the relative contribution of drying, harsh and complex while different mainly for that of surface smoothness and dynamic: the first was rather important in Sangiovese from Romagna and the second almost absent in Sagrantino. This lack of surface smoothness was also detected in Nebbiolo wines (Figure 4c). The scientific literature has no sensory data on Sagrantino wines, however, our results appear in line with previous chemical composition data. A study that measured the amount, the localisation and the extractability of flavan-3-ols and anthocyanins in 25 high-quality red grapes, classified Sagrantino grapes as the richest in extractable $\mathrm{PPh}$ and proanthocyanidins (Mattivi et al. 2002). Nebbiolo produces wines with high acidity and tannin when young, so that they require long ageing to reach a balance between acidity, astringency, full body and aroma complexity (Asproudi et al. 2015). Barbaresco wines (100\% made with Nebbiolo grapes) are often characterised by light colour and high roughness (Gerbi et al. 2006). Nebbiolo grapes are known to be poor in anthocyanins and rich in proanthocyanidins (Mattivi et al. 2002, Locatelli et al. 2016). Astringency is reported as an important sensory descriptor of SAR wines (Pagliarini et al. 2013, Laureati et al. 2014, Patrignani et al. 2017), which show the lowest level of copigmentation compared to that of the other wines (Versari et al. 2007). This could correspond to a higher astringency as a consequence of poor inclusion of some astringent monomeric components into the copigmentation stacks (Boulton 2001, Alvarez et al. 2009, Escribano-Bailón and Santos-Buelga 2012). Moreover, in recent years, unbalanced Sangiovese wines with excessive alcohol and astringency have been related to climate change (Filippetti et al. 2015). The rising temperature during ripening can negatively affect the acidity and the synthesis of PPh provoking the rise of sugar accumulation leading to excessive alcohol. Due to the importance of Sangiovese grapes and wines (the principal Italian red cultivar), this issue is of impact also taking into account the enhancing role of increased ethanol on astringency (Noble
1999), and the high maximal values observed both for the proanthocyanidins as well as for ethanol (Table 3). For the first time, our results compared Sangiovese wines from the two main areas of production showing different astringency features. Compared to SAR (Figure $4 \mathrm{~b}$ ), the astringency spectrum of SAT (Figure 4a) was different for a higher relative contribution of the complex sub-quality and an importantly lower impact of the harsh and dynamic components (mean intensities were significantly different; Tukey: $P<0.05)$. Unripe characterised the profile of Raboso wines (Figure $4 \mathrm{~h}$ ). Raboso Piave grapes are known to have high acidity and unbalanced $\mathrm{PPh}$ with predominant low molecular flavanols (catechin), leading to astringent wines not easy to drink if grape maturity, winemaking and ageing are not well managed (Mattivi et al. 2006, Corso et al. 2013). For Aglianico (Figure 4i), the pattern showed a balanced contribution of the different sub-qualities other than drying. High release and astringency of seed tannin compared to other grapes were detected in Aglianico. Studies on winemaking and ageing optimisation to smooth the astringency and balance the sourness, two sensations characterising young Aglianico wines, were carried out (Mattivi et al. 2002, Gambuti et al. 2009). In Montepulciano (Figure 4f) the important contributors, harsh and unripe, were counterbalanced by surface smoothness and complex. Only $57 \%$ of our Montepulciano samples were correctly reclassified to the corresponding single cultivar wine and for this reason the resulting astringency spectrum was the least reliable compared to that of the other cultivars. Cannonau (genetically the same cultivar as Grenache) was one of the two wines in which complex dominated (Figure 4m); following an important relative contribution of strong subqualities (drying, harsh, unripe) and also a good occurrence of surface smoothness is observed. In a comparison with a large number of Italian cultivars (Mattivi et al. 2002), Cannonau exhibited a medium or low-medium level of PPh having less than $40 \%$ of the catechins and proanthocyanidins reactive to vanillin located in the seeds, and extractable proanthocyanidins in the seeds were not exceeding $35 \%$ of PPh. In Primitivo wines the most important astringency sub-qualities were drying and complex, with a good relative contribution of surface smoothness (Figure 4e). Primitivo wines, colour intense but low in tannin concentration, commonly reach a high alcohol concentration and have a ruby-purple colour, with a sensory profile showing a good balance between astringency, body and pleasantness (Suriano et al. 2016, Trani et al. 2016). The astringency spectrum of Corvina wines (Figure $3 \mathrm{~g}$ ) was the only cultivar dominated by an unripe astringency and, at the same time, by the highest relative contribution of surface smoothness compared to that of other wines. This astringency profile fits in with previous knowledge about Corvina grapes; indeed it is reported as characterised by a low tannin concentration and a green flavour (herbaceous/ balsamic) that has been correlated to a high concentration of hexanols (Paronetto and Dellaglio 2011) and cyclic terpenes (Slaghenaufi and Ugliano 2018). Moreover, even if blended with other grapes, it gives the wine a powerful structure but surprising smoothness (Paronetto and Dellaglio 2011). Finally, Teroldego is generally characterised by an intense ruby colour and by smoothness in the mouth. Compared to other grapes, Teroldego had the highest extractable anthocyanin, showing an average concentration of extractable proanthocyanidins, with a low proportion from the seeds (Mattivi et al. 2002). Similar to Cannonau, its 
astringency spectrum (Figure 4l) was dominated by the complex sub-quality. This, together with a good surface smoothness, contrasts with the important contribution of drying and unripe with a net result, in terms of astringency, that suggest a soft mouthfeel.

\section{Correlations}

The significant correlations highlighted between sensory and chemical variables (Figure 5, Table S1) were tested across the 11 different single cultivar wines. Total phenols and proanthocyanidins were positively correlated to drying, harsh and dynamic while only negative correlation coefficients emerged between surface smoothness, unripe and complex; a weak significance was detected only for the first two. This result suggests that none of the two PPh variables tested are able to predict/measure the perception of astringency in all its possible nuances. The fact that at least some aspects of astringency could be connected to aroma compounds could partially impact on this result. Indeed, being unripe and complex, two astringency sub-qualities including a retronasal olfactory sensation (Gawel et al. 2000), the volatile composition of the wine could play a significant role on their perception. The absence of a correlation between unripe and $\mathrm{PPh}$ parameters supports the idea of a multidimensional nature of this sensory variable and appears consistent with previous findings. Indeed, in a chemosensory study aimed to characterise the fractions driving different mouthfeel properties in red wines, only the category unripe was not included in the final list of terms generated to describe the in-mouth sensations elicited during the tasting of the different odourless fractions (Sáenz-Navajas et al. 2017). The same authors tried to understand the involvement of volatile organic compounds modulating the perception of the green character of red wine astringency (SáenzNavajas et al. 2018). No specific aroma compounds were identified but a high concentration of fusel alcohols was observed and the involvement of interactions between isoamyl alcohol and anthocyanin-derivative fractions and/or tannin was suggested. Among the sensory and chemical parameters considered in this study, proanthocyanidins had the highest correlation coefficient. This is in accord with several studies that linked tannin concentration not only to the overall astringency but also to some sub-qualities describing 'aggressive' sensations (dry, pucker, chalk) and, in accord with our results, to the decrease of smooth sensations (surface smoothness, silky, velvet) (Vidal et al. 2004, 2018, Preys et al. 2006). A positive correlation was also found between the intensity of dry measured by modified progressive profiling and total tannin concentration (Kang et al. 2019). Among BCP parameters, ethanol had a negative correlation with acid and positive with bitter and this is coherent with the literature; indeed ethanol tends to increase bitterness perception (Fischer and Noble 1994, Vidal et al. 2004, Sokolowsky and Fischer 2012) and suppress sourness (Williams 1972, Gonzalo-Diago et al. 2014). Ethanol was positively correlated with drying and harsh while negatively correlated with unripe and surface smoothness. It has been reported that ethanol decreases protein-tannin interactions and this has been linked to a decrease of the overall intensity of astringency (Waterhouse et al. 2016, and references therein), while our result refers to drying that is a specific sub-quality. This result appears in line with a recent study (Sáenz-Navajas et al. 2020), where a positive correlation was found (even if not significant) between ethanol and dry. According to its definition (Gawel et al. 2000), the drying sub-quality corresponds to a lack of lubrication with dehydration, and ethanol is a dehydrating agent. It is reported that ethanol is astringent at high concentration, due to denaturation and precipitation of salivary proteins (Waterhouse et al. 2016, and references therein). In our work, we tested the correlations across the whole set of wines that, according to data reported in Table 3, includes samples with high alcohol concentration. A negative correlation between $\mathrm{pH}$ an acid taste was observed, and the $\mathrm{pH}$ was also weakly positively correlated to harsh and bitter, in line with the definition of harsh. Some studies have reported on the influence of $\mathrm{pH}$ and ethanol on the different astringency sub-qualities (Gawel et al. 2014, Kang et al. 2019). The trends that we observed for unripe appear in line with previous findings. It has been reported (De Miglio et al. 2002) that unripe was rated more intensely as ethanol concentration decreased and as the $\mathrm{pH}$ value lowered. It was suggested that the driving force of these effects could be the impact of ethanol and $\mathrm{pH}$ on the perceived acidity and this appears coherent with the definition of unripe.

The TA confirmed exactly the same correlations detected for $\mathrm{pH}$ but with an opposite trend. The weak correlation between VA and in-mouth variables could be linked to the maceration conditions during winemaking. Indeed conditions enhancing the extraction of PPh, if combined with the ethanol developed and the limited nutrient status, can stress yeast and even bacteria and may lead to a rise in VA. A recent paper identified VA among the top five predictive variables for drying and mouth-coating astringency subqualities in Tannat wines (Vidal et al. 2018).

According to our results, harsh and unripe were the subqualities that can be affected the most by BCP, while drying and even more dynamic (no correlations with BCP) appear to be driven by the composition of $\mathrm{PPh}$. Also complex and surface smoothness, the two sub-qualities describing smooth astringency, were poorly correlated to BCP. The lack of correlations between complex and PPh supports the hypothesis that other factors, likely olfactory cues, could play an important role on its perception but specific investigations are necessary.

\section{Conclusions}

Overall, this work gives a first picture of the diverse astringency of red wines from Italian native grapes, including some single cultivar products that have never been investigated before on their astringency. Furthermore, a contribution to the knowledge about the influence of chemical composition on the perception of astringency sub-qualities is given.

The 11 single cultivar wines were differentiated at least for three different levels of intensity for drying, two for harsh, unripe, dynamic, complex and velvet, while none for particulate. Despite the detected intra-cultivar variability, which was expected due to viticultural and oenological differences in commercial wine production, recurrent astringency features were found within wines from a given cultivar: intense unripe in Corvina and Raboso; low dynamic in Teroldego, Primitivo, Corvina and Montepulciano; and no velvet in Sagrantino and Nebbiolo. All samples were produced in the same vintage and had no contact with wood, therefore it appears reasonable that these recurrent features can essentially be referred to as the astringency of the grape cultivars.

The astringency spectrum, a sensory pattern describing the relative balance among six astringency sub-qualities of 
the single cultivar wines, was different from each other. Further experiments are necessary to validate these profiles on other wines produced from the same cultivars, and in limited perceptual conditions in order to evaluate the impact of cross-modal sensory interactions.

The correlation study conducted over a set of different wines confirmed the positive correlation between proanthocyanidins and astringency, highlighted that neither total phenols nor proanthocyanidins were able to measure/ predict the perception of astringency in all its nuances, and suggested that the diverse astringency sub-qualities could be affected in differently by the chemical parameters, such as ethanol or $\mathrm{pH}$.

\section{Acknowledgements}

The study was undertaken within the context of the DWines project supported by MIUR: PRIN project number: 20157RN44Y. The authors thank the wineries/consortia that provided wines, and the other components of the D-Wines project: Dr Panagiotis Arapitsas, Professor Vincenzo Gerbi, Dr Matteo Marangon, Dr Daniele Perenzoni, Professor Susana Río Segade, Dr Barbara Simonato, Dr Davide Slaghenaufi, Professor Gian Battista Tornielli, Professor Andrea Versari and Dr Simone Vincenzi.

\section{References}

Alvarez, I., Aleixandre, J.L., Garcia, M.J., Lizama, V. and Aleixandre-Tudo, J.L. (2009) Effect of the prefermentative addition of copigments on the polyphenolic composition of Tempranillo wines after malolactic fermentation. European Food Research Technology 228, 501-510.

Asproudi, A., Piano, F., Anselmi, G., Di Stefano, R., Bertolone, E. and Borsa, D. (2015) Proanthocyanidin composition and evolution during grape ripening as affected by variety: Nebbiolo and Barbera cv. Journal International des Sciences de la Vigne et du Vin 49, 59-69.

Boselli, E., Boulton, R.B., Thorngate, J.H. and Frega, N.G. (2004) Chemical and sensory characterization of DOC red wines from Marche (Italy) related to vintage and grape cultivars. Journal of Agricultural and Food Chemistry 52, 3843-3854.

Boulton, R.B. (2001) The copigmentation of anthocyanins and its role in the color of red wine: a critical review. American Journal of Enology and Viticulture 52, 67-87.

Cadena, R.S., Vidal, L., Ares, G. and Varela, P. (2014) Dynamic sensory descriptive methodologies. Time-intensity and temporal dominance of sensations. Varela, P. and Ares, G., eds. Novel techniques for sensory characterization and consumer profiling (CRC Press: Boca Raton, FL, USA) pp. 333-364.

Charters, S. and Pettigrew, S. (2007) The dimensions of wine quality. Food Quality and Preference 18, 997-1007.

Cliff, M.A., King, M.C. and Schlosser, J. (2007) Anthocyanin, phenolic composition, colour measurement and sensory analysis of BC commercial red wines. Food Research International 40, 92-100.

Corso, M., Ziliotto, F., Rizzini, F.M., Teo, G., Cargnello, G. and Bonghi, C. (2013) Sensorial, biochemical and molecular changes in Raboso Piave grape berries applying 'Double Maturation Raisonnée' and late harvest techniques. Plant Science 208, 50-57. de Luca, P., Pegan, G. and Gonzalo-Penela, C. (2019) Insights from a Google keywords analysis about Italian wine in the US market. Micro \& Macro Marketing 1, 93-1 16.

De Miglio, P., Pickering, G.J. and Reynolds, A.G. (2002) Astringent sub-qualities elicited by red wine: the role of ethanol and $\mathrm{pH}$. Cullen, C.W., Pickering, G.J. and Phillips, R., eds. Proceedings of the international Bacchus to the future conference; 23 April-15 May 2002; St Catharines, ON, Canada (Brock University Press: St Catherines, ON, Canada) pp. 31-52.

Di Stefano, R., Cravero, M.C. and Gentilini, N. (1989) Metodi per lo studio dei polifenoli dei vini. L'Enotecnico 25, 83-89.

Dravnieks, A. (1982) Odor quality: semantically generated multidimensional profiles are stable. Sciences 218, 799-801.

Escribano-Bailón, M.T. and Santos-Buelga, C. (2012) Anthocyanin copigmentation-evaluation, mechanisms and implications for the colour of red wines. Current Organic Chemistry 16, 715-723.
Ferrer-Gallego, R., Hernández-Hierro, J.M., Rivas-Gonzalo, J.C. and Escribano-Bailón, M.T. (2014) Sensory evaluation of bitterness and astringency sub-qualities of wine phenolic compounds: synergistic effect and modulation by aromas. Food Research International 62, 1100-1 107.

Ferrer-Gallego, R., Brás, N.F., García-Estévez, I., Mateus, N., RivasGonzalo, J.C., De Freitas, V. and Escribano-Bailón, M.T. (2016) Effect of flavonols on wine astringency and their interaction with human saliva. Food Chemistry 209, 358-364.

Filippetti, I., Movahed, N., Allegro, G., Valentini, G., Pastore, C., Colucci, E. and Intrieri, C. (2015) Effect of post-veraison source limitation on the accumulation of sugar, anthocyanins and seed tannins in Vitis vinifera cv. Sangiovese berries. Australian Journal of Grape and Wine Research 21, 90-100.

Fischer, U. and Noble, A.C. (1994) The effect of ethanol, catechin concentration, and $\mathrm{pH}$ on sourness bitterness of wine. American Journal of Enology and Viticulture 45, 6-10.

Francis, I.L., Gawel, R., Iland, P.G., Vidal, S., Cheynier, V., Guyot, S., Kwiatkowski, M.J. and Waters, E.J. (2002) Characterising mouth-feel properties of red wines. Australian and New Zealand Wine Industry Journal 17(3), 18, 21-22, 24-25.

Gambuti, A., Capuano, R., Lecce, L., Fragasso, M.G. and Moio, L. (2009) Extraction of phenolic compounds from 'Aglianico' and 'Uva di Troia' grape skin and seeds in model solutions: influence of ethanol and maceration time. Vitis 48, 193-200.

Gawel, R., Iland, P.G. and Francis, I.L. (2001) Characterizing the astringency of red wine: a case study. Food Quality and Preference 12, 83-94.

Gawel, R., Oberholster, A. and Francis, I.L. (2000) A 'Mouth-feel Wheel': terminology for communicating the mouth-feel characteristics of red wine. Australian Journal of Grape and Wine Research 6, 203-207.

Gawel, R., Day, M., Van Sluyter, S.C., Holt, H., Waters, E.J. and Smith, P.A. (2014) White wine taste and mouthfeel as affected by juice extraction and processing. Journal of Agricultural and Food Chemistry 62, 10008-10014.

Gerbi, V., Caudana, A., Rolle, L.G., Cagnasso, E. and Zeppa, G. (2006) La vinificazione del Nebbiolo. Quaderni di Viticoltura ed Enologia dell'università di Torino 28, 167-184.

Gonzalo-Diago, A., Dizy, M. and Fernández-Zurbano, P. (2013) Taste and mouthfeel properties of red wines proanthocyanidins and their relation to the chemical composition. Journal of Agricultural and Food Chemistry 61, 8861-8870.

Gonzalo-Diago, A., Dizy, M. and Fernández-Zurbano, P. (2014) Contribution of low molecular weight phenols to bitter taste and mouthfeel properties in red wines. Food Chemistry 154, 187-198.

Green, B.G. (1993) Oral astringency: a tactile component of flavor. Acta Psychologica 84, 119-125.

Guinard, J.X., Pangborn, R.M. and Lewis, M.J. (1986) The timecourse of astringency in wine upon repeated ingestion. American Journal of Enology and Viticulture 37, 184-189.

Kang, W., Niimi, J., Muhlack, R.A., Smith, P.A. and Bastian, S.E.P. (2019) Dynamic characterization of wine astringency profiles using modified progressive profiling. Food Research International 120, 244-254.

Lacombe, T., Audeguin, L., Boselli, M., Bucchetti, B., Cabello, F., Chatelet, P., Crespan, M., D'Onofrio, C., Eiras Dias, J., Ercisli, S., Gardiman, M., Grando, M.S., Jandurova, O., Jung, A., Kiss, E., Kozma, P., Maul, E., Maghradze, D., Martinez, M.C., Muñoz, G., Pátková, J.K., Pejic, I., Peterlunger, E., Pitsoli, D., Preiner, D., Raimondi, S., Regner, F., Savin, G., Savvides, S., Schneider, A., Spring, J.L., Szoke, A., Veres, A., Boursiquot, J.M., Bacilieri, R. and This, P. (2011) Grapevine European catalogue: towards a comprehensive list. Vitis 50, 65-68.

Laureati, M., Gaeta, D. and Pagliarini, E. (2014) Qualitative and sensory evaluation of Sangiovese red wine obtained from organically and conventionally grown grapes. Italian Journal of Food Science 26, 355-362.

Lelièvre, M., Chollet, S., Abdi, H. and Valentin, D. (2008) What is the validity of the sorting task for describing beers? A study using trained and untrained assessors. Food Quality and Preference 19, 697-703.

Locatelli, M., Travaglia, F., Coïsson, J.D., Bordiga, M. and Arlorio, M. (2016) Phenolic composition of Nebbiolo grape (Vitis vinifera L.) from Piedmont: characterization during ripening of grapes selected in different geographic areas and comparison with Uva Rara and Vespolina cv. European Food Research and Technology 242, 1057-1068.

Mannini, F. (2004) Italian indigenous grapevine cultivars: guarantee of genetic biodiversity and economic resource. Acta Horticulturae 652, 87-95. 
Mattivi, F., Zulian, C., Nicolini, G. and Valenti, L. (2002) Wine, biodiversity, technology, and antioxidants. Annals of the New York Academy of Sciences 957, 37-56.

Mattivi, F., Vrhovsek, U., Masuero, D. and Trainotti, D. (2009) Differences in the amount and structure of extractable skin and seed tannins amongst red grape varieties. Australian Journal of Grape and Wine Research 15, 27-35.

Mattivi, F., Guzzon, R., Vrhovsek, U., Stefanini, M. and Velasco, R. (2006) Metabolite profiling of grape: flavonols and anthocyanins. Journal of Agricultural and Food Chemistry 54, 7692-7702.

Mercurio, M.D., Dambergs, R.G., Cozzolino, D., Herderich, M.J. and Smith, P.A. (2010) Relationship between red wine grades and phenolics. 1. Tannin and total phenolics concentrations. Journal of Agricultural and Food Chemistry 58, 12313-12319.

Mueller, S., Osidacz, P., Francis, I.L. and Lockshin, L. (2010) Combining discrete choice and informed sensory testing in a two-stage process: can it predict wine market share? Food Quality and Preference 21, 741-754.

Noble, A.C. (1999) Why do wines taste bitter and feel astringent. Chemistry of wine flavour. Volume 714. ACS Symposium Series (American Chemical Society: Washington, DC, USA) pp. 156-165. Organisation Internationale de la Vigne et du Vin (2015) Compendium of international methods of must and wine analysis (Organisation Internationale de la Vigne et du Vin: Paris, France).

Organisation Internationale de la Vigne et du Vin (2017) Vine varieties distribution in the world (Organisation Internationale de la Vigne et du Vin: Paris, France). http://www.oiv.int/public/medias/ 5336/infographie-focus-oiv-2017-new.pdf

Pagliarini, E., Laureati, M. and Gaeta, D. (2013) Sensory descriptors, hedonic perception and consumer's attitudes to Sangiovese red wine deriving from organically and conventionally grown grapes. Frontiers in Psychology 4, 896.

Paronetto, L. and Dellaglio, F. (2011) Amarone: a modern wine coming from an ancient production technology. Advances in Food and Nutrition Research 63, 285-306.

Patrignani, F., Montanari, C., Serrazanetti, D.I., Braschi, G., Vernocchi, P., Tabanelli, G., Parpinello, G.P., Versari, A., Gardini, F. and Lanciotti, R. (2017) Characterisation of yeast microbiota, chemical and sensory properties of organic and biodynamic Sangiovese red wines. Annals of Microbiology 67, 99-109.

Peynaud, E. (1987) The taste of wine: the art and science of wine appreciation (Macdonald Orbis: London, England).

Piacenza, M., Benfratello, L. and Sacchetto, S. (2009) Taste or reputation? What drives market prices in the wine industry? Estimation of a hedonic model for Italian premium wines. Applied Economics 41, 2197-2209.

Ployon, S., Morzel, M., Belloir, C., Bonnotte, A., Bourillot, E., Briand, L., Lesniewska, E., Lherminier, J., Aybeke, E. and Canon, F. (2018) Mechanisms of astringency: structural alteration of the oral mucosal pellicle by dietary tannins and protective effect of bPRPs. Food Chemistry 253, 79-87.

Preys, S., Mazerolles, G., Courcoux, P., Samson, A., Fischer, U., Hanafi, M., Bertrand, D. and Cheynier, V. (2006) Relationship between polyphenolic composition and some sensory properties in red wines using multiway analyses. Analytica Chimica Acta 563, 126-136. Sáenz-Navajas, M.P., Martín-López, C., Ferreira, V. and FernándezZurbano, P. (2011) Sensory properties of premium Spanish red wines and their implication in wine quality perception. Australian Journal of Grape and Wine Research 17, 9-12.

Sáenz-Navajas, M.P., Ferrero-del-Teso, S., Jeffery, D.W., Ferreira, V. and Fernández-Zurbano, P. (2020) Effect of aroma perception on taste and mouthfeel dimensions of red wines: correlation of sensory and chemical measurements. Food Research International 131, 108945.

Sáenz-Navajas, M.P., Campo, E., Avizcuri, J.M., Valentin, D., Fernández-Zurbano, P. and Ferreira, V. (2012) Contribution of non-volatile and aroma fractions to in-mouth sensory properties of red wines: wine reconstitution strategies and sensory sorting task. Analytica Chimica Acta 732, 64-72.

Sáenz-Navajas, M.P., Avizcuri, J.M., Echávarri, J.F., Ferreira, V., Fernández-Zurbano, P. and Valentin, D. (2016) Understanding quality judgements of red wines by experts: effect of evaluation condition. Food Quality and Preference 48, 216-227.

Sáenz-Navajas, M.P., Avizcuri, J.-M., Ferrero-del-Teso, S., Valentin, D., Ferreira, V. and Fernández-Zurbano, P. (2017) Chemo-sensory characterization of fractions driving different mouthfeel properties in red wines. Food Research International 94, 54-64.

Sáenz-Navajas, M.P., Arias, I., Ferrero-del-Teso, S., FernándezZurbano, P., Escudero, A. and Ferreira, V. (2018) Chemo-sensory approach for the identification of chemical compounds driving green character in red wines. Food Research International 109, 138-148.

Singleton, V.L., Orthofer, R. and Lamuela-Raventós, R.M. (1999)

Analysis of total phenols and other oxidation substrates and antioxidants by means of Folin-Ciocalteu reagent. Methods in Enzymology 299, 152-178.

Slaghenaufi, D. and Ugliano, M. (2018) Norisoprenoids, sesquiterpenes and terpenoids content of Valpolicella wines during aging: investigating aroma potential in relationship to evolution of tobacco and balsamic aroma in aged wine. Frontiers in Chemistry 6, 66.

Sokolowsky, M. and Fischer, U. (2012) Evaluation of bitterness in white wine applying descriptive analysis, time-intensity analysis, and temporal dominance of sensations analysis. Analitica Chimica Acta 732, 46-52.

Suriano, S., Alba, V., Di Gennaro, D., Basile, T., Tamborra, M. and Tarricone, L. (2016) Major phenolic and volatile compounds and their influence on sensorial aspects in stem-contact fermentation winemaking of Primitivo red wines. Journal of Food Science and Technology 53, 3329-3339

Torchio, F., Cagnasso, E., Gerbi, V. and Rolle, L. (2010) Mechanical properties, phenolic composition and extractability indices of Barbera grapes of different soluble solids contents from several growing areas. Analytica Chimica Acta 660, 183-189.

Trani, A., Verrastro, V., Punzi, R., Faccia, M. and Gambacorta, G. (2016) Phenols, volatiles and sensory properties of primitivo wines from the 'Gioia Del Colle' PDO area. South African Journal of Enology and Viticulture 37, 139-148.

Versari, A., Parpinello, G.P. and Mattioli, A.U. (2007) Characterisation of colour components and polymeric pigments of commercial red wines by using selected UV-Vis spectrophotometric methods. South African Journal of Enology and Viticulture 28, 6-10.

Vidal, L., Antúnez, L., Giménez, A., Medina, K., Boido, E. and Ares, G. (2016) Dynamic characterization of red wine astringency: case study with Uruguayan Tannat wines. Food Research International 82, 128-135.

Vidal, L., Antúnez, L., Giménez, A., Medina, K., Boido, E. and Ares, G. (2017) Sensory characterization of the astringency of commercial Uruguayan Tannat wines. Food Research International 102, 425-434.

Vidal, L., Antúnez, L., Rodríguez-Haralambides, A., Giménez, A., Medina, K., Boido, E. and Ares, G. (2018) Relationship between astringency and phenolic composition of commercial Uruguayan Tannat wines: application of boosted regression trees. Food Research International 112, 25-37.

Vidal, S., Courcoux, P., Francis, I.L., Kwiatkowski, M., Gawel, R., Williams, P., Waters, E.J. and Cheynier, V. (2004) Use of an experimental design approach for evaluation of key wine components on mouth-feel perception. Food Quality and Preference 15, 209-217.

Waterhouse, A.L., Sacks, G.L. and Jeffery, D.W. (2016) Understanding wine chemistry (John Wiley: Hoboken, NJ, USA).

Williams, A.A. (1972) Flavour effects of ethanol in alcoholic beverages. The Flavour Industry 3, 604-606.

Wine Australia (2019) National vintage report (Wine Australia: Adelaide, SA, Australia). https://www.wineaustralia.com/getmedia/ 807bf053-3692-448a-9ed5-c0084a47elbb/Vintage-report-2019_fullversion.pdf 